\title{
Exploring the relationship between accreditation and patient satisfaction - the case of selected Lebanese hospitals
}

\author{
Wissam Haj-Ali' ${ }^{1}$ Lama Bou Karroum ${ }^{2}$, Nabil Natafgi ${ }^{3}$, Kassem Kassak ${ }^{2, *}$
}

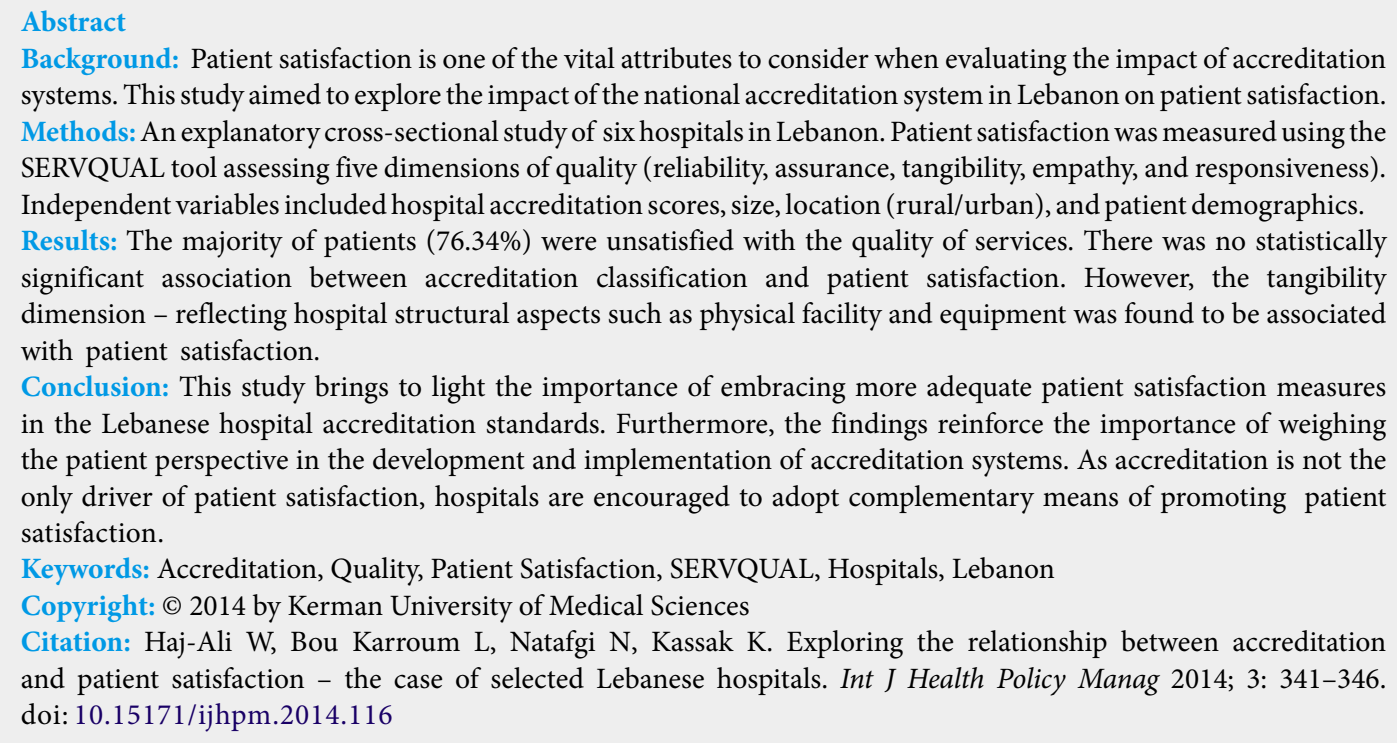

Background: Patient satisfaction is one of the vital attributes to consider when evaluating the impact of accreditation systems. This study aimed to explore the impact of the national accreditation system in Lebanon on patient satisfaction. Methods: An explanatory cross-sectional study of six hospitals in Lebanon. Patient satisfaction was measured using the SERVQUAL tool assessing five dimensions of quality (reliability, assurance, tangibility, empathy, and responsiveness). Independent variables included hospital accreditation scores, size, location (rural/urban), and patient demographics. Results: The majority of patients (76.34\%) were unsatisfied with the quality of services. There was no statistically significant association between accreditation classification and patient satisfaction. However, the tangibility dimension - reflecting hospital structural aspects such as physical facility and equipment was found to be associated with patient satisfaction.

Conclusion: This study brings to light the importance of embracing more adequate patient satisfaction measures in the Lebanese hospital accreditation standards. Furthermore, the findings reinforce the importance of weighing the patient perspective in the development and implementation of accreditation systems. As accreditation is not the only driver of patient satisfaction, hospitals are encouraged to adopt complementary means of promoting patient satisfaction.

Keywords: Accreditation, Quality, Patient Satisfaction, SERVQUAL, Hospitals, Lebanon

Copyright: (C) 2014 by Kerman University of Medical Sciences

Citation: Haj-Ali W, Bou Karroum L, Natafgi N, Kassak K. Exploring the relationship between accreditation and patient satisfaction - the case of selected Lebanese hospitals. Int J Health Policy Manag 2014; 3: 341-346. doi: 10.15171/ijhpm.2014.116

Article History:

Received: 2 July 2014 Accepted: 30 October 2014 ePublished: 3 November 2014

\section{Key Messages}

Implications for policy makers

- The results from this study indicate that the current hospital accreditation system in Lebanon may not necessarily translate into enhanced patient satisfaction. To that end, there is an opportunity to enhance the national hospital accreditation system with additional standards that promote patient satisfaction in Lebanese hospitals.

- This study also highlights the importance of routine collection of patient satisfaction data in a structured and standardized manner.

- Hospital decision-makers are encouraged to treat accreditation as a means-to-an-end rather than an end by itself and adopt complementary measures that aim to improve patient satisfaction.

Implications for public

Recommendations for decision-makers stemming from this article are believed to translate to policies that aim to enhance public satisfaction in Lebanese hospitals. Furthermore, the study is expected to raise awareness about patients' considerations while choosing service providers. Since accreditation is not the only driver for satisfaction, the public is encouraged to have an enlightened and informed decision when selecting hospitals from where services are sought.

\section{Introduction}

Accreditation programs, which have been implemented in many developing countries, are used as a regulatory tool to ensure quality of service and efficient use of resources $(1,2)$. Health organizations use this system to evaluate their processes and improve the quality of services delivered (3). Quality, as a concept, has multiple dimensions, one of which is patient satisfaction. Satisfaction is an important dimension that reflects patients' perceptions of 'how well' the services provided are meeting their needs and expectations. In addition, it is considered an important outcome indicator for assessing the quality of care delivered (4-6). Patient satisfaction surveys are regarded as an important method of empowering patients. In fact, from an ethical perspective, empowering patients and enhancing their autonomy are considered fundamental features in the delivery of care (7). Healthcare managers can benefit from satisfaction ratings to enhance structures, processes and outcomes of care, $(5,8)$ as well as pinpoint areas for improvement (9). It has been well-established that customer satisfaction results in patients 
returning to the same hospital for care, therefore increasing the hospital's overall profit margin $(10,11)$. Patient satisfaction survey results can be useful for forecasting future trends in patient preferences and choice of hospitals. On a wider scale, understanding patient perception of quality presents policymakers with an opportunity to design national strategies that improve the quality of care and enhance service utilization in hospitals.

Evaluating the relationship between patient satisfaction and accreditation scores is important for assessing the impact of accreditation systems; however, the few studies that have addressed this question have failed to detect an association (11-14).

A study conducted by Heuer in 2004 attempted to clarify the relationship between the two quality indicators, accreditation and patient satisfaction (11). Retrospective review of 41 hospitals' accreditation scores from the Joint Commission on Accreditation of Healthcare Organizations and their patient satisfaction rating data were analyzed. The results failed to show a relationship between the accreditation score, which represents technical quality, and patient satisfaction rating, which represents service quality.

Another study conducted by Hayati et al. in 2010 compared inpatient satisfaction in medical surgical wards between accredited and non-accredited hospitals in Malaysia (12). Socio-demographic factors influencing patient satisfaction were also assessed in this study. The SERVQUAL questionnaire was used and the results showed that there was no significant difference in patient satisfaction between accredited and non-accredited hospitals. In both accredited and non-accredited hospitals, satisfaction level was inversely proportional to educational level and monthly income, and directly proportional to age. Employed respondents were found to have lower satisfaction levels than the unemployed. The study concluded that accreditation is not highly reflective of patient satisfaction.

In the cardiology units of 25 hospitals in Germany, Sack et al. conducted a study to assess the relationship between accreditation status and patient satisfaction (13). The Picker Inpatient questionnaire, which assesses seven dimensions of patient satisfaction, was used. The results of this study, which included more than 3,000 discharged patients, did not find a significant correlation between patient satisfaction and accreditation status of hospitals.

In 2011, Sack et al. studied the relationship between hospitals' accreditation status and patient satisfaction by assessing how willing patients' were to recommend the hospital (14). The study included data from 36,777 randomly selected inpatients from 73 different hospitals. The findings of the study did not show an association between recommendation rate and accreditation, but found that even though hospital accreditation is a step towards total quality management, it is not necessarily a crucial factor for quality of care.

Findings from these studies indicate that the accreditation process may not be a highly reflective measure of patient satisfaction. Therefore, healthcare organizations are encouraged to adopt a multidimensional approach that combines different quality-enhancing parameters. However, patient satisfaction is still an important quality indicator that needs to be assessed while questioning newly established accreditation programs for their impact on quality. When adopting a national accreditation program in Lebanon, it is rational to question if this system is improving patient satisfaction and meeting their expectations. As Heuvel pointed out, some believe that quality aims at reaching perfection by minimizing deficiencies and meeting the exact specification every time a certain service is delivered, while others define quality as meeting the customer's needs, requirements and expectations (15).

\section{Lebanese context}

Lebanon is one of the first countries in the Eastern Mediterranean Region (EMR) to implement a comprehensive accreditation system (16). In 2000, the Lebanese Ministry of Public Health (MoPH) introduced this system using a phased approach to ensure a smooth transition for hospitals. Through the accreditation system, the $\mathrm{MoPH}$ intended to incorporate a continuous quality improvement process in the daily operations of hospitals and to contract only with those that provide safe, efficient and good quality services (17). In an attempt to incentivize hospitals to become accredited, the $\mathrm{MoPH}$ in Lebanon linked any contractual agreements with hospitals to the results of the accreditation process (17). The MoPH contracted an Australian consultant team to develop and implement a system for evaluating the quality of care in Lebanese hospitals. The accreditation process was implemented in four phases. First, the standards were piloted and followed by an initial survey. Afterwards, the standards were revised and a second survey was performed. All hospitals that are contracted with the MoPH for treatment of patients were included in the national hospital survey in an attempt to assess all contracted hospitals against the basic accreditation standards. Out of the 142 hospitals surveyed, 57 were not granted an accredited status. The remaining 85 accredited hospitals were classified into 4 categories: 15 hospitals in category "A", 8 in category "B", 36 in category "C" and 26 in category "D" (18). These categories differ by the level of hospital compliance to the standards. Hospitals classified as " $\mathrm{A}$ " were the most compliant and those classified as " $\mathrm{D}$ " were the least compliant. The results reported in this study were based on the second and latest available national cycle of accreditation (2005-6) at the time of data collection. At that time, hospitals were preparing to engage in the third and latest cycle of national accreditation.

Essentially, the national hospital accreditation system in Lebanon was created in response to "the absence of an effective consumer voice", an issue that served as an "impetus for change" (3). The MoPH argues that the Lebanese consumer has a weak role and is often uninformed or even misled, which deprives the system of an important driving force towards better quality. Therefore, according to the argument raised by the $\mathrm{MoPH}$, the accreditation system was purposefully designed to enhance the quality of care, while acting as a vehicle to enhance consumer choices. To this end, this study was aimed at evaluating this specific objective of the MoPH by examining the association between the newly designed accreditation system in Lebanon and patient satisfaction with hospital services. Although some pioneer studies assessed 
the impact of the Lebanese accreditation scheme from the provider perspective, none tackled the issue from the patient perspective. In light of limited evidence on the influence of accreditation from the standpoint of patients in the Middle East and North Africa (MENA) region (19), this study aimed to explore the relationship between patient satisfaction and hospitals' classification according to the Lebanese MoPH accreditation survey results. Patient satisfaction in relation to patient socio-demographic variables and hospitals geographic locations are also investigated in this study.

\section{Methods}

Study design and data sources

The study employs an observational cross-sectional design and was conducted during the spring of 2011. To ensure diversity among the sampled hospitals, participating hospitals were randomly chosen after stratification based on size, accreditation classification and geographic location (rural/ urban). Two groups of hospitals were compared for their patient satisfaction results. The first group included highly classified hospitals (A and B based on the MoPH accreditation survey classification results; more compliant with the accreditation standards) and the second group included poorly classified hospitals ( $\mathrm{C}$ and $\mathrm{D}$; less compliant with the accreditation standards). Hospital characteristics and contact information were obtained from a publicly-accessible list generated by the Syndicate of Private Hospitals in Lebanon. Hospitals accreditation classification was obtained from the $\mathrm{MoPH}$ based on the second national survey (2005-6 cycle).

\section{Survey instrument}

The SERVQUAL or RATER was developed to measure five dimensions of quality from the perspective of the patient; reliability, assurance, tangibles, empathy and responsiveness $(20,21)$. The five dimensions are defined as follow: i) reliability, the capability to provide an accurate and dependable service; ii) assurance, the politeness and the knowledge of the employees and their ability to provide confidence and trust; iii) tangibility, the physical structure, equipment, personnel and the readability of the communication material; iv) empathy, the provision of attention and the level of caring for customers; v) responsiveness, the provision of timely service and the willingness to help customers. Each dimension consists of four to five items totaling 22 pairs; 11 items assessing patients' perceptions (P) and 11 assessing patients' expectations (E). Each item consists of a seven point Likert-scale ranging from strongly disagree ' 1 ' to strongly agree ' 7 '. For this study, the translated and validated Arabic version of the questionnaire was used (22). The first part of the questionnaire gathered information on patient socio-demographic data (age, gender, monthly income, educational level) and the second part assessed patient satisfaction. SERVQUAL has been widely examined for its validity and reliability in different fields, including healthcare (12,20-24). However, despite its popularity and widespread application, the SERVQUAL survey has been criticized for its focus on processes more than outcomes, and its limited ability to capture variance and context-specific meanings (21). In addition, an important area of criticism of SERVQUAL, is its use of gap scores (P-E) in the measurement of service quality (25-27).

\section{Data collection process}

Six hospitals were chosen based on size, accreditation classification, and geographic location. To ensure diversity among the sampled hospitals, guided by a purposive sampling technique, three hospitals were chosen from classes $\mathrm{A}$ and $\mathrm{B}$ and the other three from classes $\mathrm{C}$ and $\mathrm{D}$ based on the $\mathrm{MoPH}$ accreditation classification results. The administrative consent of the participating hospitals was obtained through an authorization letter provided to the administration. Given the total bed size of the six participating hospitals (total of 786 beds), the recommended sample size was 259 patients based on $5 \%$ margin of error, confidence level of $95 \%$ and response distribution of $50 \%$.

In order to judge the quality of services in a rational and credible manner, inclusion criteria included patients aged between 18 and 80 years old, literate, conscious, not critically ill and admitted to the medical and surgical wards of an accredited Lebanese hospital. Further, patients were chosen to be in their third day of hospitalization at least, so that they would have spent enough time at the hospital to accurately report their perceived quality of care. On the day of data collection, each hospital provided members of the study team a list of all the patients present at the hospital who met the inclusion criteria. Members of the study team selected participants by choosing every other patient on the hospital list (random assortment of patients). Patients were approached by the study team on the same day and were informed about the purpose and benefits of the study. Eligibility was reconfirmed verbally with patients who were interested in participating. The Arabic or the English version of the questionnaire was used according to the participant's preference. The majority of the patients requested that the surveyors read, explain and fill the questionnaires according to their verbal responses. As a result, though efforts were made to standardize the way the surveyors approached and explained the questions to the patients, the answers may still have been subject to interviewer bias. To ensure the confidentiality and privacy of the participants, healthcare providers were not present during the administration of the questionnaire. Recruitment of patients continued until the desired sample size for each accreditation classification was reached. A total of 279 patients volunteered to fill-in the survey and were included in the study. Data collection took nearly 2-12 hour visits per hospital at an average of 30 minutes per survey.

\section{Data Analysis}

Patient satisfaction scores were calculated by subtracting the reported Expectations scores from the reported Perception scores (P-E) (20). A negative score would reflect the patient's dissatisfaction with service quality as the quality of service perceived by the patient would be lower than the patient's expectation, whereas a positive score would reflect the patient's satisfaction with the service quality as their perception of the quality of service would be higher than their expectations (28). Descriptive statistics (means and 
standard deviations or percentages) were used to summarize key patient and hospital characteristics. These variables were further explored with regard to accreditation classification of hospitals (A\&B vs. C\&D) using Pearson's Chi-square test and Fisher's exact test for count data. Statistical associations were revealed through cross tables. To assess the relationship between hospital classification and patient satisfaction multinomial logistic regression analyses was conducted with 'educational' level as a covariate at the patient level and 'hospital size' at the hospital level. A significance level of 5\% was applied and P-values were determined using SPSS 18.0 (SPSS Inc., Chicago, IL, USA).

\section{Results}

The key characteristics of accredited hospitals are shown in Table 1 . The majority of patients $(n=213,76.34 \%)$ were dissatisfied with the quality of services delivered in the six hospitals. The results in Table 1 show that most of the participants in the study were between the ages of 65-80. Furthermore, the majority of patients sampled had attained a maximum of secondary-level education. No significant association was observed between patient characteristics, such as age, gender, income, and education level, and their satisfaction with the quality of services provided by the hospital (Table 1). With respect to accreditation classification, close to significant difference was observed in patient satisfaction among A and B classified hospitals (28.00\%) versus $\mathrm{C}$ and $\mathrm{D}$ classified hospitals (18.61\%). The majority of patients who were satisfied with the quality of care they received were from hospitals $\mathrm{A}$ and $\mathrm{B}$. On the other hand, dissatisfaction with quality of care was reported in near equal amounts across all the hospitals/both hospital classes. Additionally, there was no significant association between the geographic location of the hospital and the patient satisfaction. The multinomial logistic regression model was employed to assess the association between hospital classification and patient satisfaction. After adjusting for confounders, the association between hospital classification and patient satisfaction was not found to be significant $(P=0.10)$. After adjusting for gender, age and educational level the relationship between a hospital's geographic location and the dependent variable remained insignificant.

Patient satisfaction was further analyzed in relation to the five dimensions of service quality: tangibility, reliability, responsiveness, assurance and empathy (Table 2). Only the tangibility dimension was found to be significantly associated with hospitals' accreditation classification $(P<0.01)$. The results demonstrated that $42.00 \%$ of the patients in $\mathrm{A}$ and $\mathrm{B}$ classified hospitals were satisfied with the physical component as opposed to only $15.00 \%$ satisfaction rate for those in hospitals classified $\mathrm{C}$ and $\mathrm{D}$.

\section{Discussion}

Accreditation is an established tool that promotes optimal standards and improves process and outcomes in healthcare (1). While evaluating accreditation systems, patient satisfaction remains a vital outcome to be assessed. To our knowledge, this is one of the first studies to investigate the

Table 1. Descriptive statistics for patients and hospital

\begin{tabular}{|c|c|c|c|c|c|}
\hline \multirow[b]{2}{*}{ Observational unit } & \multirow[b]{2}{*}{ Variable } & \multirow[b]{2}{*}{$\begin{array}{l}\text { Total } \\
\mathrm{N}(\%)\end{array}$} & \multicolumn{2}{|c|}{ Patient satisfaction* } & \multirow{2}{*}{$P$-value } \\
\hline & & & $\begin{array}{l}\text { Not satisfied } \\
213(76.34 \%)\end{array}$ & $\begin{array}{c}\text { Satisfied } \\
66(23.66 \%)\end{array}$ & \\
\hline \multirow[t]{19}{*}{ Patient } & Gender & & & & 0.21 \\
\hline & Male & $120(43.01)$ & $96(45.07)$ & $24(36.36)$ & \\
\hline & Female & 159 (56.99) & $117(54.93)$ & $42(63.64)$ & \\
\hline & Age (years) & & & & 0.86 \\
\hline & $18-25$ & $28(10.04)$ & 20 (9.39) & $8(12.12)$ & \\
\hline & $26-34$ & $28(10.04)$ & $23(10.80)$ & $5(7.58)$ & \\
\hline & $35-50$ & $83(29.75)$ & $65(30.52)$ & $18(27.27)$ & \\
\hline & $51-64$ & $63(22.58)$ & $48(22.54)$ & $15(22.73)$ & \\
\hline & $65-80$ & $77(27.60)$ & $57(26.76)$ & $20(30.30)$ & \\
\hline & Education & & & & 0.10 \\
\hline & University & $44(15.77)$ & $36(16.90)$ & $8(12.12)$ & \\
\hline & Secondary & 109 (39.07) & $89(41.78)$ & $20(30.30)$ & \\
\hline & Primary & $85(30.47)$ & $57(26.76)$ & $28(42.42)$ & \\
\hline & Less than primary & $41(14.70)$ & $31(14.55)$ & $10(15.15)$ & \\
\hline & Monthly income (US dollar) & & & & 0.23 \\
\hline & $<500$ & 106 (37.99) & 79 (37.09) & $27(40.91)$ & \\
\hline & $>500$ and $\leq 1000$ & 139 (49.82) & 110 (51.64) & 29 (43.94) & \\
\hline & $>1000$ and $\leq 3000$ & $33(11.83)$ & $24(11.27)$ & $9(13.64)$ & \\
\hline & $>3000$ & $1(0.36)$ & $0(0.00)$ & $1(1.52)$ & \\
\hline \multirow[t]{7}{*}{ Hospital } & Hospital classification & & & & 0.07 \\
\hline & $A \& B$ & $150(53.76)$ & $108(50.70)$ & $42(63.64)$ & \\
\hline & $C \& D$ & $129(46.24)$ & $105(49.30)$ & $24(36.36)$ & \\
\hline & Geographic area & & & & 0.21 \\
\hline & Shouf & $92(32.97)$ & 66 (30.99) & $26(39.39)$ & \\
\hline & Beirut & $87(31.18)$ & $72(33.80)$ & $15(22.73)$ & \\
\hline & Saida & $100(35.84)$ & $75(35.21)$ & $25(37.88)$ & \\
\hline
\end{tabular}

*Based on the results of the 2006 accreditation cycle in six Lebanese hospitals 
Table 2. Comparing patient satisfaction stratified by the five dimensions of service quality with the hospitals accreditation classification*

\begin{tabular}{|c|c|c|c|c|c|}
\hline & \multicolumn{2}{|c|}{ Class A\&B } & \multicolumn{2}{|c|}{ Class C\&D } & \multirow[b]{2}{*}{$P$-value } \\
\hline & $\begin{array}{c}\text { Not satisfied } \\
\text { N (\%) }\end{array}$ & $\begin{array}{c}\text { Satisfied } \\
\mathbf{N}(\%) \\
\end{array}$ & $\begin{array}{c}\text { Not satisfied } \\
\mathrm{N}(\%) \\
\end{array}$ & $\begin{array}{c}\text { Satisfied } \\
\mathrm{N}(\%) \\
\end{array}$ & \\
\hline Tangibility & $87(58.00)$ & $63(42.00)$ & $109(84.50)$ & $20(15.50)$ & $<0.01$ \\
\hline Reliability & $104(69.33)$ & $46(30.67)$ & 101 (78.29) & $28(21.71)$ & 0.09 \\
\hline Responsiveness & $102(68.00)$ & $48(32.00)$ & 85 (65.89) & $44(34.11)$ & 0.71 \\
\hline Assurance & $99(66.00)$ & $51(34.00)$ & 90 (69.77) & $39(30.23)$ & 0.50 \\
\hline Empathy & $100(66.67)$ & $50(33.33)$ & $96(74.42)$ & $33(25.58)$ & 0.16 \\
\hline
\end{tabular}

*Based on the results of the 2006 accreditation cycle in six Lebanese hospitals

relationship between the national hospital accreditation system and patient satisfaction in the $\operatorname{EMR}(1,29)$.

The study results revealed that the majority of patients (76.34\%) were dissatisfied with the quality of services delivered in the six hospitals under review in the study. This raises a concern about the adopted approach in Lebanese hospitals to meet the expectations of their patients. In contrast to the literature findings $(12,30)$, results did not show significant associations between patient satisfaction, the hospital's geographic location, and any of the patient's socio-demographic characteristics. Although not statistically significant, the study results supported the trend identified in the literature (12), namely that educational level and monthly income are inversely proportional to patient satisfaction, whereas age is directly proportional to patient satisfaction. After adjusting for confounders including gender, age, educational level and hospital size, the association between a hospital's accreditation classification and patient satisfaction was not found to be significant. However, upon further analysis of satisfaction in relation to the five dimensions of service quality, patient satisfaction was found mostly to be driven by the tangibility dimension. This may reflect the notion that patients are mostly satisfied with the hospital's appearance, physical facilities and equipment and rather than the processes and outcomes of care. This observation is expected and valid as patients usually limit their assessment of the hospital to their satisfaction with visible and tangible physical characteristics (31,32). In fact, no significant association was noted between hospital accreditation classification and the remaining four dimensions, reliability, responsiveness, assurance and empathy. Such a finding can be explained by the argument that A and B classified hospitals tend to have more structural investment capabilities reflected in enhanced physical facilities and advanced equipment (17). The study findings are in line with the literature which showed that the relationship between accreditation and patient satisfaction was not well-established $(12,13)$. In a study conducted by Heuer in 2004, no relationship was established between patient satisfaction level and hospitals' accreditation scores based on the Joint Commission on Accreditation of Healthcare Organizations (11). The study concluded that there is no relationship between service quality represented by patient satisfaction scores and technical quality represented by the accreditation score. It is worth noting that accreditation contains other constructs and domains that are not strictly related to patient satisfaction, such as structural, procedural and technical aspects, which enhance quality of care yet are not necessarily visible to patients $(11,14)$. Assessing these constructs was beyond the scope of this study.
A limitation of this study is the fact that data collection coincided with the hospitals preparation for the 2011 accreditation survey. During this period hospitals tend to be at an enhanced performance level, which might positively affect patient satisfaction scores. Additionally, patient satisfaction was assessed using a quantitative questionnaire, which may not have provided a comprehensive reflection of patient perception of services that could have been achieved using qualitative methods. Another limitation is the fact that patient satisfaction - the outcome measure of this study - is not an immediate result that can be promptly assessed, but a distant outcome that is the result of consistent good quality care. An additional limitation that merits consideration is the small sample size of the study which might limit the generalizability of the results. Hence, the results and conclusions in this study should be interpreted carefully, acknowledging the impact of a small sample size on the investigated relationship between hospital accreditation and patient satisfaction. Additionally, the purposive sampling approach adopted to selected hospitals is non-probabilistic. However, this approach was chosen to ensure a reasonable balance of size, accreditation classification and geographic diversity among the investigated hospitals.

\section{Conclusion}

In summary, this explanatory study of a sample of Lebanese hospitals revealed that the majority of patients were dissatisfied with the quality of services provided. Therefore Lebanese hospitals are encouraged to adopt additional means to improve customer satisfaction among all five dimensions of the service quality. Training staff on value of care and the importance of understanding the external customer expectation have been proven to be effective (6). The adoption of balanced scorecards integrating different patient-centered quality indicators, one of which is patient satisfaction, can also facilitate bringing the customers perspective into hospitals planning and priorities (12).

Despite the absence of a robust correlation between accreditation and patient satisfaction, it is still believed that patient centeredness is a critical construct to be considered in the development and implementation of any accreditation system. To that end, implications from this study reveal that there is an opportunity for the implementation of additional standards aimed at enhancing the national hospital accreditation system and promoting patient satisfaction in Lebanese hospitals. In particular, an enrichment opportunity lies in improving the dimensions related to the provision of reliable, assured, empathic, and responsive services to patients. The system can build on its current structure and processfocused standards to expand on outcome oriented ones that 
can positively impact patient satisfaction. Furthermore, given the fact that this study revealed that the majority of patients are dissatisfied with the quality of the services they received, there is a huge benefit from developing a standardized tool for assessing patient satisfaction in Lebanese hospitals. The standardized tool can be promoted and recommended by the national accreditation system, thus incentivizing Lebanese hospital to collect and report patient satisfaction data. In fact, national data on patient satisfaction can inform policies on the system/organizational level, and quality improvement on the practice level, to help Lebanese hospitals progress towards a more coordinated and sustainable approach of meeting their patients' expectations.

\section{Ethical issues}

The study was approved by the American University of Beirut Institutional Review Board.

\section{Competing interests}

The authors declare that they have no competing interests.

\section{Authors' contributions}

WHA, LBK, and KK contributed to the design and conceptualization of the paper. WHA and LBK coordinated data collection, review, and data analysis. WHA and NN prepared the first draft. WHA and NN formulated the final review of inputs and feedback from all coauthors and integrated the final version. All authors reviewed and approved the final version.

\section{Authors' affiliations}

IInstitute of Health Policy, Management and Evaluation, University of Toronto, Toronto, Ontario, Canada. ${ }^{2}$ Department of Health Management and Policy, Faculty of Health Sciences, American University of Beirut, Beirut, Lebanon. ${ }^{3}$ Department of Health Management and Policy, College of Public Health, University of lowa, lowa City, IA, USA.

\section{References}

1. Greenfield D, Braithwaite J. Health sector accreditation research: a systematic review. Int J Qual Health Care 2008; 20: 172-83. doi: 10.1093/intqhc/mzn005

2. Jovanovic B. Hospital Accreditation as Method for Assessing Quality in Healthcare. Arch Oncol 2005; 13: 156-7.

3. Ammar W, Wakim IR, Hajj I. Accreditation of hospitals in Lebanon: a challenging experience. East Mediterr Health $J$ 2007; 13: 138-49.

4. Tzeng HM, Chang Y. Patient satisfaction versus quality. Nurs Ethics 2008; 15: 121-4. doi: 10.1177/0969733007080210

5. Labarere J, Francois P, AuquierP, Robert C, Fourny M. Development of a French inpatient satisfaction questionnaire. Int J Qual Health Care 2001; 13: 99-108. doi: 10.1093/intqhc/13.2.99

6. Shaikh BT, Mobeen N, Azam SI, Rabani F. Using SERVQUAL for assessing and improving patient satisfaction at a rural health facility in Pakistan. East Mediterr Health J 2008; 14: 447-56.

7. Grol R. Improving the quality of medical care: building bridges among professional pride, payer profit, and patient satisfaction. JAMA 2001; 286: 2578-85. doi: 10.1001/jama.286.20.2578

8. Bell R, Krivich MJ, Boyd MS. Charting patient satisfaction. Mark Health Serv 1997; 17: 22-9.

9. Draper M, Cohen P, Buchan H. Seeking consumer views: What use are results of hospital patient satisfaction surveys? Int $J$ Qual Health Care 2001; 13: 463-8. doi: 10.1093/intqhc/13.6.463

10. Walker $\mathrm{R}$, Johnson L, Leonard S. Re-thinking the conceptualization of customer value and service quality within the service-profit chain. Manag Serv Qual 2006; 16: 23-36. doi: 10.1108/09604520610639946

11. Heuer AJ. Hospital Accreditation and Patient Satisfaction: Testing the Relationship. J Healthc Qual 2004; 26: 46-51. doi: 10.1111/j.1945-1474.2004.tb00471.x
12. Hayati NI, Azimatun NA, Rozita H, Ezat WA, Rizal AM. InPatients' Satisfaction In The Medical And Surgical Wards - A Comparison Between Accredited And Non Accredited Hospital In The State Of Selangor. J Commun Health 2010; 16: 60-8.

13. Sack $C$, Lütkes $P$, Günther W, Erbel R, Jockel K, Holtmann JG. Challenging the holy grail of hospital accreditation: A cross sectional study of inpatient satisfaction in the field of cardiology. Health Serv Res 2010; 10: 120. doi: 10.1186/1472-6963-10-120

14. Sack C, Scherag A, Lutkes P, Gunther W, Jockel KH, Holtmann G. Is there an association between hospital accreditation and patient satisfaction with hospital care? A survey of 37,000 patients treated by 73 hospitals. Int J Qual Health Care 2011; 23: 278-83. doi: 10.1093/intqhc/mzr011

15. Heuvel J, Bogers A, Does R, Dijk S, Berg M. Quality Management: Does it Pay Off? Quality Management in Health Care 2006; 15: 137-49. doi: 10.1097/00019514-200607000-00003

16. El-Jardali F, Jamal D, Dimassi H, Ammar W, Tchaghchaghian V.The impact of hospital accreditation on quality of care: perception of Lebanese nurses. Int J Qual Health Care 2008; 20: 363-71. doi: 10.1093/intqhc/mzn023

17. Ammar W. Health Beyond Politics. Beirut: World health organization eastern Mediterranean office; 2009.

18. El-Jardali F. Hospital accreditation policy in Lebanon: Its potential for quality improvement. J Med Liban 2007; 55: 39-45.

19. El-Jardali F, Makhoul J, Jamal D, Ranson M, Kronfol N, Tchaghchagian V. Eliciting policymakers' and stakeholders' opinions to help shape health system research priorities in the Middle East and North Africa region. Health Policy Plan 2009; 25: 15-27. doi: 10.1093/heapol/czp059

20. Parasuraman A, ZeithamI VA, Berry LL. SERVQUAL: a multipleitem scale for measuring customer perceptions of service quality. J Retailing 1988; 64: 12-40.

21. Buttle F. SERVQUAL: review, critique, research agenda. Eur J Marketing 1996; 30: 8-32.

22. Mostafa MM. An empirical study of patients' expectations and satisfactions in Egyptian hospitals. Int J Health Care Qual Assur Inc Leadersh Health Serv 2005; 18: 516-32.

23. Babakus E, Mangold WG. Adapting the SERVQUAL scale to the health care environment: an empirical assessment. In: Bloom P, Parasuraman A, editors. Enhancing Knowledge Development in Marketing. Chicago, IL: American Marketing Association; 1989.

24. Babakus E, Mangold WG. Adapting the SERVQUAL scale to hospital services: an empirical investigation. Health Serv Res 1992; 26: 767-86.

25. Cronin J, Taylor S. Measuring service quality: a reexamination and extension. Journal of Marketing 1992; 56: 55-68. doi: $10.2307 / 1252296$

26. Cronin J, Taylor S. SERVPERF vs SERVQUAL: reconciling performances based perception - minus - expectations measurement of service quality. Journal of Marketing 1994; 58 : 125-31. doi: 10.2307/1252256

27. Mehta S, Durvasula S. Relationship Between SERVQUAL Dimensions and Organizational Performance in the Case of a Business-to-Business Service. Journal of Business \& Industrial Marketing 1998; 13: 40-53. doi: 10.1108/08858629810206232

28. Bowers M, Kiefe C. Measuring Healthcare Quality: Comparing and Contrasting the Medical and Marketing Approaches. Am J Med Qual 2002; 17: 136-44. doi: 10.1177/106286060201700403

29. Saleh S, Alameddine M, Natafgi M, Mourad Y. Quality of Care in Primary Health Care Settings in the Eastern Mediterranean Region: A Systematic Review of the Literature. 2014; Under review.

30. Rahmqvist M. Patient satisfaction in relation to age, health status, and other background factors: a model for comparisons of care units. Int J Qual Health Care 2001; 13: 385-90. doi: 10.1093/intqhc/13.5.385

31. Sitzia J, Wood N. Patient satisfaction: A review of issues and concepts. Soc Sci Med 1997; 45: 1829-43. doi: 10.1016/s02779536(97)00128-7

32. Abramowitz S, Cote A, Berry E. Analyzing patient satisfaction: a multianalytic approach. Quality Review Bulletin 1987; 13: 12230. 